\title{
Rho/ROCK-dependent inhibition of 3T3-L1 adipogenesis by G-protein-deamidating dermonecrotic toxins: differential regulation of Notch1, Pref1/DIk1, and $\beta$-catenin signaling
}

\author{
Yuka Bannai ${ }^{1 \neq}$, Leila R. Aminova ${ }^{1+\neq}$, Melinda J. Faulkner ${ }^{1+}$, Mengfei Ho $^{1}$ and Brenda A. Wilson ${ }^{1,2 *}$ \\ 1 Department of Microbiology, University of Illinois at Urbana-Champaign, Urbana, IL, USA \\ ${ }^{2}$ Host-Microbe Systems Theme, Institute for Genomic Biology, University of Illinois at Urbana-Champaign, Urbana, IL, USA
}

Edited by:

Ken Bradley, University of California, Los Angeles, USA

\section{Reviewed by:}

Marina Santic', University of Rijeka, Croatia

Jason Larabee, University of

Oklahoma Health Science Center, USA

\section{*Correspondence:}

Brenda A. Wilson, Department of Microbiology, University of Illinois at Urbana-Champaign, 601 South

Goodwin Avenue, Urbana, IL 61801,

USA.

e-mail: bawilson@life.illinois.edu

${ }^{\dagger}$ Present Address:

Leila R. Aminova, ZuChem Inc., 801

W. Main Street, Peoria, IL 61606,

USA.

Melinda J. Faulkner, Department of Biology, Bradley University, Peoria,

IL 61625, USA.

\#These authors contributed equally to this work.
The dermonecrotic toxins from Pasteurella multocida (PMT), Bordetella (DNT), Escherichia coli (CNF1-3), and Yersinia (CNFY) modulate their G-protein targets through deamidation and/or transglutamination of an active site GIn residue, which results in activation of the $G$ protein and its cognate downstream signaling pathways. Whereas DNT and the CNFs act on small Rho GTPases, PMT acts on the a subunit of heterotrimeric $G_{q}$, $G_{i}$, and $\mathrm{G}_{12 / 13}$ proteins. We previously demonstrated that PMT potently blocks adipogenesis and adipocyte differentiation in a calcineurin-independent manner through downregulation of Notch1 and stabilization of $\beta$-catenin and Pref1/DIk1, key proteins in signaling pathways strongly linked to cell fate decisions, including fat and bone development. Here, we report that similar to PMT, DNT, and CNF1 completely block adipogenesis and adipocyte differentiation by preventing upregulation of adipocyte markers, PPAR $\gamma$ and $\mathrm{C} / \mathrm{EBP} \alpha$, while stabilizing the expression of Pref1/Dlk1 and $\beta$-catenin. We show that the Rho/ROCK inhibitor Y-27632 prevented or reversed these toxin-mediated effects, strongly supporting a role for Rho/ROCK signaling in dermonecrotic toxin-mediated inhibition of adipogenesis and adipocyte differentiation. Toxin treatment was also accompanied by downregulation of Notch1 expression, although this inhibition was independent of Rho/ROCK signaling. We further show that PMT-mediated downregulation of Notch1 expression occurs primarily through $\mathrm{G}_{12 / 13}$ signaling. Our results reveal new details of the pathways involved in dermonecrotic toxin action on adipocyte differentiation, and the role of Rho/ROCK signaling in mediating toxin effects on Wnt/ $\beta$-catenin and Notch1 signaling, and in particular the role of $G_{q}$ and $G_{12 / 13}$ in mediating PMT effects on Rho/ROCK and Notch1 signaling.

\section{INTRODUCTION}

Members of the dermonecrotic toxin family of large G-proteinmodifying bacterial protein toxins are considered the causative agents or are associated with the major symptoms of a number of epizootic and zoonotic diseases (Roop et al., 1987; De Rycke et al., 1990; Woolfrey and Moody, 1991; Blanco et al., 1992; Foged, 1992; Horiguchi, 2001; Brockmeier et al., 2002; Arashima and Kumasaka, 2005; Diavatopoulos et al., 2005; Knust and Schmidt, 2010; Wilson and Ho, 2011). The cytotoxic necrotizing factors from Escherichia coli (CNF1, CNF2, and CNF3) and Yersinia pseudotuberculosis (CNFY) and the dermonecrotic toxin from Bordetella spp. (DNT) modify and constitutively activate the small Rho GTPases, RhoA, Rac1, and Cdc42 (Hoffmann and Schmidt, 2004; Knust and Schmidt, 2010), leading to actin cytoskeletal rearrangements and changes in cell morphology. CNF1, CNF2, and $\mathrm{CNF} 3$ deamidate a specific Gln residue at the active site of the Rho GTPases, RhoA (Gln63), Rac1 (Gln61), and Cdc42 (Gln61) (Hoffmann and Schmidt, 2004; Knust and Schmidt, 2010), while CNFY acts only on RhoA (Gln63) (Hoffmann et al.,
2004). Although DNT can modify the same Gln residue on each of these G proteins through deamidation, it does so primarily through transglutamination (Schmidt et al., 1999, 2001). The dermonecrotic toxin from Pasteurella multocida (PMT) also activates small Rho GTPases (Ohnishi et al., 1998; Orth et al., 2005), but only indirectly through deamidation of analogous active site Gln residues in the $\alpha$ subunits of its target heterotrimeric $G$ proteins, $\mathrm{G}_{\mathrm{i}}(\mathrm{G} \ln 205), \mathrm{G}_{\mathrm{q}}(\mathrm{Gln} 209)$, or $\mathrm{G}_{12 / 13}$ (Gln229) (Orth et al., 2005, 2009; Kamitani et al., 2011; Wilson and Ho, 2011). Remarkably, although all of the dermonecrotic toxins are deamidases and DNT and the CNFs share strong sequence similarity in their catalytic domains, PMT does not have any sequence or structural similarity with DNT or the CNFs (Wilson and Ho, 2010, 2011).

Bone resorption and subsequent atrophic rhinitis are characteristic outcomes attributed to the actions of PMT and DNT on differentiation and/or proliferation of osteoblasts and osteoclasts during respiratory infections in animals with their respective bacterial pathogens (Ackermann et al., 1995, 1996; 
Sterner-Kock et al., 1995; Gwaltney et al., 1997; Mullan and Lax, 1998; Brockmeier et al., 2002; Harmey et al., 2004; Hildebrand et al., 2010). Since bone-forming osteoblasts and marrow adipocytes share a common mesenchymal stem cell origin, it is anticipated that these dermonecrotic toxins might also affect adipocyte differentiation. Indeed, there is some evidence that PMT exposure results in reduced body weight and fat in experimental animals (Cheville and Rimler, 1989; Thurston et al., 1992; Ackermann et al., 1995, 1996). In support of this, we previously demonstrated that PMT treatment prevents adipocyte differentiation and blocks adipogenesis in cultured 3T3-L1 cells (Aminova and Wilson, 2007). We showed that PMT prevented expression of key adipocyte-specific markers, $\mathrm{C} / \mathrm{EBP} \alpha$ and PPAR $\gamma$, in 3T3$\mathrm{L} 1$ preadipocytes and downregulated these markers in mature adipocytes. We also showed that PMT prevented the downregulation of Pref1 (also called Dlk1), an EGF-like transmembrane protein that is highly expressed in certain tumors and carcinomas (Huang et al., 2007; Dezso et al., 2008; Jin et al., 2008; Yanai et al., 2010; Xu et al., 2012) and that is strongly downregulated in adipocytes (Boney et al., 1996; Garces et al., 1999; Sul, 2009). We further showed that PMT completely downregulates Notch1 mRNA and protein expression, while stabilizing $\beta$-catenin protein levels (Aminova and Wilson, 2007). Notch1 and $\mathrm{Wnt} / \beta$-catenin signaling pathways are involved in pivotal cell fate decisions (Andersson et al., 2011).

$\mathrm{G}_{\mathrm{q}}$-PLC $\beta 1$ activation of calcium signaling is known to block adipogenesis through activation of $\mathrm{Ca}^{2+}$-calmodulindependent calcineurin signaling (Neal and Clipstone, 2002; Liu and Clipstone, 2007). However, we previously found that the inhibitory effects of PMT on adipocyte differentiation and Notch 1 could not be reversed by treatment with the calcineurin inhibitor cyclosporine A (CsA) (Aminova and Wilson, 2007), suggesting that PMT-induced $\mathrm{G}_{\mathrm{q}}$-PLC $\beta 1$ activation of calcium signaling is not the only signaling pathway mediated by PMT to block adipocyte differentiation. Although the connection between G-protein signaling and Notch1 signaling in adipogenesis is not fully understood, we considered the possibility that PMT-mediated blockade of adipocyte differentiation and adipogenesis might occur through its indirect action on Rho-GTPases through other heterotrimeric $G$ proteins, such as $G_{12 / 13}$. To explore this possibility, we first examined whether the other dermonecrotic toxins, DNT and CNF1, which directly modify and activate Rho-GTPases and do not act on heterotrimeric G proteins, might also inhibit 3T3-L1 differentiation and adipogenesis, and if so, whether they modulate Notch 1 and $\beta$-catenin levels similar to PMT. Two isoforms of Rho-associated kinases (ROCK1 and ROCK2) mediate downstream signaling of Rho proteins, leading to actin reorganization, formation of actin filaments and focal adhesions, and contractility (Amano et al., 2010). Since inhibition of ROCK signaling is known to enhance adipogenesis (Noguchi et al., 2007), we examined whether inhibition of Rho/ROCK signaling might counteract the toxin-mediated effects on 3T3-L1 cells.

Herein, we report that similar to PMT, both DNT and CNF1 completely block adipogenesis and adipocyte differentiation by preventing expression of PPAR $\gamma$ and $\mathrm{C} / \mathrm{EBP} \alpha$, maintaining expression of Pref1/Dlk1 and $\beta$-catenin, and downregulating expression of Notch1. We also show that the Rho/ROCK inhibitor Y-27632 prevented or reversed these toxin-mediated effects and that PMT-mediated downregulation of Notch 1 occurs primarily through $\mathrm{G}_{12 / 13}$ signaling.

\section{MATERIALS AND METHODS RECOMBINANT TOXINS}

The pQE-CNF1 vector was provided kindly from Dr. Alison D. O'Brian at the Uniformed Services University (Mills et al., 2000). The pTHB-DNT vector was constructed by subcloning the DNT gene into the BamHI and KpnI sites the expression vector pTrcHisB (Invitrogen). The DNT gene was generated by PCR and subcloning using two overlapping DNT gene fragments from plasmids pDNT103 and pDNT115, kindly obtained from Dr. Alison A. Weiss at the University of Cincinnati (Walker and Weiss, 1994). His 6 -tagged recombinant toxin proteins (rCNF1, rDNT, and rPMT) were purified using methods essentially as previously described for rPMT (Aminova and Wilson, 2007), except rCNF1 and rDNT were expressed in Escherichia coli XL1Blue cells under the induction of IPTG. Toxin concentrations were determined by NIH Image J digital image analysis of Pierce GelCode Blue-stained SDS-PAGE gels, using BSA as the standard. The toxins were stored at $-80^{\circ} \mathrm{C}$ until use. Biological activity of rPMT, rDNT, and rCNF were confirmed by cell morphology assay, as previously described for rPMT (Wilson et al., 2000; Repella et al., 2011), and by NFAT-luciferase activation assay, as previously described for rPMT (Aminova et al., 2008).

\section{CELL CULTURE}

Murine 3T3-L1 preadipocytes (ATCC, CL-173) were maintained at $37^{\circ} \mathrm{C}$ and $5 \%$ carbon dioxide in normal $10 \%$ fetal bovine serum (FBS, Atlanta Biologicals)-medium, consisting of Dulbecco's Modified Eagle's Medium (DMEM, Invitrogen) supplemented with $10 \%$ heat-inactivated FBS, $\mathrm{pH} 7.4,100$ units/mL penicillin $\mathrm{G}$, and $100 \mu \mathrm{g} / \mathrm{mL}$ streptomycin.

\section{FLUORESCENCE MICROSCOPY}

3T3-L1 cells were treated overnight with the indicated amount of toxins in the presence or absence of $10 \mu \mathrm{M}$ ROCK inhibitor, Y-27632 (Sigma, cat \#Y0503). Cells were then washed three times with $1 x$ phosphate buffered saline (PBS) and treated with $0.5 \%$ formaldehyde for $15 \mathrm{~min}$. Cells were washed three times with PBS, treated with $0.1 \%$ Triton X-100, washed again with PBS and treated with TRITC-phalloidin (Sigma, cat \#P1951) to stain F-actin and DAPI (Sigma, cat \#D9564) to stain nuclei before washing and visualizing by fluorescence microscopy. Images were taken using an Olympus IX-70 inverted fluorescence microscope equipped with a digital camera (Olympus DP70).

\section{T3-L1 CELL DIFFERENTIATION}

Differentiation studies using 3T3-L1 cells were done essentially as previously described with slight modification (Aminova and Wilson, 2007). In brief, 3T3-L1 cells were plated onto a 6-well plate and grown for 5-6 days until confluence, changing the medium every 2 days. Two days post-confluence, denoted as day 0 , the cells were induced to differentiate in the presence or absence of $1 \mathrm{nM}$ of the indicated toxin in normal $10 \%$ 
FBS-DMEM or in differentiation medium (DM), consisting of normal 10\% FBS-DMEM with $1 \mu \mathrm{M}$ dexamethasone (Sigma, cat \#D2915), $0.5 \mathrm{mM}$ 3-isobutyl-1-methylxanthine (Sigma, cat \#I5879), and $10 \mu \mathrm{g} / \mathrm{mL}$ of bovine insulin (Sigma, cat \#I6634). Two days after differentiation induction, the medium was changed to post-DM, consisting of normal 10\% FBS-DMEM with $10 \mu \mathrm{g} / \mathrm{mL}$ of insulin. In the case of experiments involving treatment with ROCK inhibitor, Y-27632, cells were induced to differentiate in the presence or absence of $10 \mu \mathrm{M}$ Y-27632 and $1 \mathrm{nM}$ of the indicated toxin. Toxins were removed on day 2, but Y-27632 was maintained throughout the differentiation process.

\section{OIL RED 0 STAINING AND LIPID QUANTIFICATION}

Accumulation of oil droplets during adipogenesis was visualized by Oil Red $\mathrm{O}$ staining, as previously described (Aminova and Wilson, 2007). Phase-contrast microscopy images were taken using an Olympus IX-70 inverted microscope equipped with a digital camera (Olympus DP70). Lipid accumulation was measured by absorbance at $490 \mathrm{~nm}$ using a microplate reader (BioTek Synergy HT). In the case of toxin dose experiments, the reading for oil accumulation was expressed as a percentage of that observed for fully differentiated cells. The experiments were repeated at least three times.

\section{IMMUNOBLOTTING}

3T3-L1 cells were washed with cold PBS and lysed by incubation in lysis buffer [ $50 \mathrm{mM}$ Tris- $\mathrm{HCl}, \mathrm{pH} 7.0$, containing $1 \%$ SDS, $10 \%$ glycerol, $2 \mathrm{mM} \mathrm{Na} \mathrm{VO}_{4}, 2 \mathrm{mM}$ EGTA, and a protease inhibitor cocktail (Sigma, cat\#P8340) with benzonase (Sigma, cat\#E8263)]. After $20 \mathrm{~min}$ of incubation on ice, cell lysates were centrifuged at $12,000 \times \mathrm{g}$ for $10 \mathrm{~min}$ at $4^{\circ} \mathrm{C}$. Total protein concentrations were determined by using Bio-Rad Protein Assay reagent (Bio-Rad). Proteins were separated by SDS-PAGE, transferred to PVDF membrane (Osmonics), and analyzed by Western blot, using standard procedures. Primary antibodies were used against the following: Pref1/Dlk1 (\#AB3511) from Chemicon Int.; PPAR $\gamma$ (sc-7196), C/EBP $\alpha$ (sc-61), $\beta$-catenin (sc-7963), $\beta$-actin (sc-4777), and Notch1 (sc-6015) from Santa Cruz Biotechnology. Specific protein bands were visualized by the ECL Plus System (Amersham) using HRP-conjugated secondary antibodies (Santa Cruz Biotechnology or Sigma). $\beta$-actin was used as internal protein loading controls. However, when comparing treatments in differentiated and undifferentiated cells, there are no ideal controls for protein levels due to the inherent changes in cellular protein levels associated with proliferation/differentiation that occur in response to treatments. For this reason, in cases of toxin treatments of differentiated adipocytes, where levels of housekeeping genes such as $\beta$-actin significantly change in response to treatment, each experimental treatment was compared pairwise without or with treatment and the total protein content of each sample was first analyzed by Coomassie staining to normalize for loading.

\section{ShRNA KNOCKDOWN}

Short hairpin RNAs (shRNAs), corresponding to the G $\alpha$ and GFP genes were designed according to the manufacturer's instructions. Target sequences for shRNA against $\mathrm{G}_{\mathrm{q}}: 5^{\prime}$-GGAA
GCCCGGAGGATCAAC-3 $3^{\prime}$; G $\alpha_{12}: 5^{\prime}$-GCGACACCATCTTCGAC AACA-3'; G $\alpha_{13}$ : 5'-TGGGTGAGTCTGTAAAGTATT-3'; and GFP: $5^{\prime}$-GCAAGCTGACCCTGAAGTTC-3'. shRNAs were cloned into the pSuperRetro vector (OligoEngine, WA) under the control of polymerase-III H1-RNA gene promoter. Oligonucleotides were annealed and cloned into the BglII/HindIII site of the vector. The MLV-based viruses were generated by tripartite transfection of HEK-293T cells using packing plasmids from Harvard Gene Therapy Initiative, Boston. Virus titer was estimated by quantifying the number of HEK-293T cells surviving after incubation in medium containing puromycin $(4 \mu \mathrm{g} / \mathrm{mL}$; Sigma, cat\#P8833). 3T3-L1 cells, maintained as above, were plated onto 12-well plates at the density of $5 \times 10^{4}$ cells $/ \mathrm{mL}$ for $16 \mathrm{~h}$. Cells were then infected with retroviruses at a titer of $10^{9} / \mathrm{mL}$ in the presence of $4 \mu \mathrm{g} / \mathrm{mL}$ Polybrene (Sigma, cat\#AL-118) at an MOI of 10 and, after incubation for $24 \mathrm{~h}$ virus-infected cells were selected by treatment for at least 1 week with puromycin $(4 \mu \mathrm{g} / \mathrm{mL})$.

\section{RT-PCR}

3T3-L1 cells in $60 \mathrm{~mm}$ culture dishes were treated as described above. Total RNA was prepared using RNeasy Miniprep Kit (Qiagen). Total RNA was quantified using a Genesys 2 UV-Vis spectrophotometer (Spectronics), and samples were stored at $-80^{\circ} \mathrm{C}$ until analysis. The levels of mRNA expression were determined by RT-PCR using Reverse-iT RT-PCR kit (ABgene). Reverse transcription was performed at $55^{\circ} \mathrm{C}$ for $30 \mathrm{~min}$, followed by PCR in the same tube. To determine the linear range of cycle numbers for each primer set, RT-PCR was performed with different RNA amounts from untreated cells at day 0 (for genes with maximum expression level in preadipocytes) and in mature adipocytes at day 7 (no treatment with the toxin). RT-PCR products were analyzed using ethidium bromide-stained agarose gel electrophoresis. The mRNA expression levels of Notch1 and the housekeeping gene for GAPDH were determined by using published primer sets (Garces et al., 1997). The mRNA expression levels of $\mathrm{G} \alpha_{\mathrm{q}}, \mathrm{G} \alpha_{11}, \mathrm{G} \alpha_{12}$, and $\mathrm{G} \alpha_{13}$ were determined by using the following primer sets: $\mathrm{G} \alpha_{\mathrm{q}}$ : forward-AGGCTCATGCACAAT TGGTTCG, reverse-GATAGGAAGGGTCGGCTACACG; Ga $\alpha_{11}$ : forward-GGCCAATGCACTCCTGATCCG, reverse-GGTAGCCT ACTGTGGCGATG; G $\alpha_{12}$ : forward-CGGCTGGTCAAGATCC TGCT, reverse-AGAGTGCTGCCAGGGAATGC; $\mathrm{G}_{13}$ : forwardTCCGTGCTGTCCGTGTGCTT, reverse-GGTTTTTGTTATCT CCCCAGGG.

\section{STATISTICS}

All data shown are representative of at least three independent experiments performed in triplicate and are presented as the mean \pm standard deviation. Comparisons between groups were made using the Student's paired $t$-test (Excel statistics package), where statistical significance was defined as $P<0.05$.

\section{RESULTS \\ EFFECT OF TOXINS ON MURINE 3T3-L1 CELL MORPHOLOGY AND STRESS FIBER FORMATION}

Undifferentiated murine 3T3-L1 preadipocytes treated with $0.5 \mathrm{nM}$ rPMT or rDNT formed a dense monolayer with cells clustering into discrete patches or "foci" (Figure 1A), similar to what 


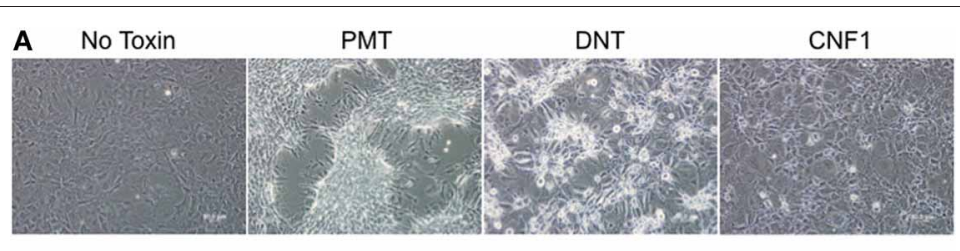

B

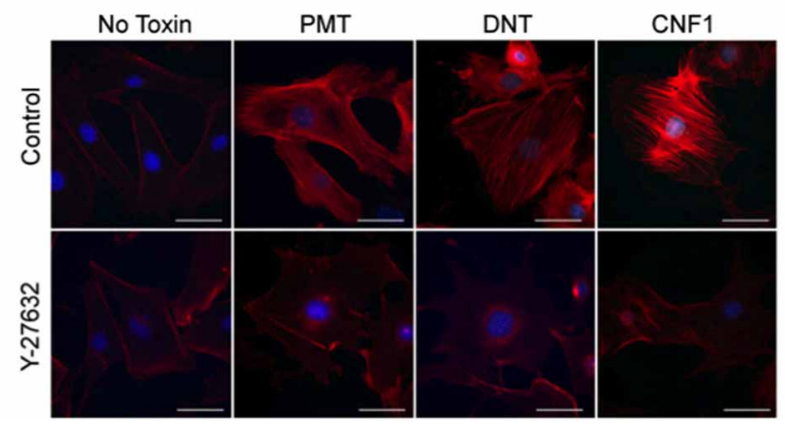

FIGURE 1 | Effect of dermonecrotic toxins on 3T3-L1 preadipocyte cell morphology and stress fiber formation. (A) Phase-contrast images of confluent, undifferentiated 3T3-L1 cell monolayers treated continuously for 5 days with $0.5 \mathrm{nM}$ of the indicated toxin. (B) Fluorescence microscopy images of undifferentiated 3T3-L1 cells treated for $16 \mathrm{~h}$ with $1 \mathrm{nM}$ of the indicated toxin in the absence (top panels) or presence (bottom panels) of $10 \mu \mathrm{M}$ Y-27632. Red, TRITC-phalloidin staining of F-actin, showing stress fibers resulting from toxin treatment. Blue, DAPI staining of cell nuclei. Bar, $50 \mu \mathrm{m}$. was reported before for rPMT-treated or rDNT-treated fibroblasts (Horiguchi et al., 1995, 1997; Dudet et al., 1996; Lacerda et al., 1996; Wilson et al., 2000; Aminova and Wilson, 2007). rCNF1treated 3T3-L1 cells, on the other hand, showed cell spreading and enlargement with multi-nucleation but without proliferation, similar to what was reported before for rCNF1-treated fibroblasts (Falzano et al., 1993; Fiorentini et al., 1997). These changes were accompanied in each case by increased formation of actin stress fibers (Figure 1B, upper panel), similar to that reported previously (Falzano et al., 1993; Horiguchi et al., 1995, 1997; Dudet et al., 1996; Lacerda et al., 1996; Fiorentini et al., 1997; Wilson et al., 2000; Aminova and Wilson, 2007). However, formation of stress fibers was blocked when cells were treated with toxin in the presence of the Rho-associated protein kinase (ROCK) inhibitor, Y-27632 (Figure 1B, lower panel).

\section{EFFECT OF TOXINS ON 3T3-L1 DIFFERENTIATION AND ADIPOGENESIS}

3T3-L1 cell differentiation was induced in the absence or presence of $0.5 \mathrm{nM}$ of rPMT, rDNT, or rCNF1. Lipid accumulation was visualized 7 days after induction of differentiation by Oil Red $\mathrm{O}$ staining of the lipid droplets. As shown in Figure 2A, after induction of differentiation, 3T3-L1 cells developed into round adipocytes containing abundant lipid droplets that stained red (control). In contrast, 3T3-L1 cells treated with rPMT, rDNT, or rCNF1 at the time of differentiation induction, failed to differentiate into adipocytes, similar to and in agreement with what was reported previously for PMT (Aminova and Wilson, 2007). Instead, in all three cases the cells formed a dense monolayer with little $(\leq 20 \%)$ accumulation of lipid (Figure 2B). This inhibition of adipogenesis was dose-dependent (Figure 2C), with DNT and CNF1 effecting 70-80\% inhibition at $50 \mathrm{pM}$, while PMT was more potent showing $>80 \%$ inhibition at $10 \mathrm{pM}$.

\section{EFFECT OF ROCK INHIBITOR Y-27632 ON TOXIN-MEDIATED BLOCKADE OF ADIPOGENESIS}

To determine whether toxin-mediated inhibition of adipogenesis could be rescued by inhibiting Rho/ROCK signaling, 3T3-L1 cells were treated with Y-27632 in the presence of toxins. Y-27632 co-treatment resulted in partial override of the toxin-mediated blockade of differentiation and lipid accumulation for the case of rPMT and rDNT (30 and 53\%, respectively) and a 76\% override in the case of rCNF1 (Figures 2A,B), even at toxin concentrations up to 100 -fold higher than needed to block adipogenesis.

\section{EFFECT OF TOXINS ON ADIPOGENESIS MARKER EXPRESSION DURING 3T3-L1 DIFFERENTIATION}

Protein expression patterns of adipogenesis markers were monitored over the course of 3T3-L1 differentiation in the presence or absence of $1 \mathrm{nM}$ of rPMT, rDNT, or rCNF1. As expected during normal differentiation (Figure 3A, far left panels), preadipocytes exhibited high levels of Pref1/Dlk1 protein expression at the onset of differentiation induction, but Pref1/Dlk1 levels were absent by day 4 and remained undetectable in mature adipocytes. PPAR $\gamma$ and $\mathrm{C} / \mathrm{EBP} \alpha$ protein expression levels, on the other hand, were upregulated by day 4 and remained high in mature adipocytes. In contrast, while Pref1/Dlk1 protein levels decreased by about half on day 2, similar to the control, in the presence of any of the toxins the levels were restored by day 4 and were maintained high thereafter (Figure 3A, right panels). Toxin treatment completely blocked induction of protein expression of the two major adipocyte markers, PPAR $\gamma$ and $\mathrm{C} / \mathrm{EBP} \alpha$.

\section{EFFECT OF ROCK INHIBITOR Y-27632 ON TOXIN-MEDIATED BLOCKADE OF ADIPOGENESIS}

Since Y-27632 treatment appeared to counteract the toxinmediated blockade of adipogenesis (Figure 2), we next examined 




whether inhibition of Rho/ROCK signaling could overcome toxin-mediated downregulation of adipocyte markers, $\operatorname{PPAR} \gamma$ and $\mathrm{C} / \mathrm{EBP} \alpha$, upon differentiation induction in 3T3-L1 preadipocytes. As shown in Figure 3B, Y-27632 was able to partially prevent the downregulation of PPAR $\gamma$ and $\mathrm{C} / \mathrm{EBP} \alpha$ by all three toxins, but more so in the case of CNF1. Y-27632 was also able to dampen the toxin-mediated upregulation of Pref1/Dlk1 in all cases, although again more so for CNF1 than PMT or DNT. In contrast, Y-27632 was not able to counteract the downregulation of PPAR $\gamma$ and $\mathrm{C} / \mathrm{EBP} \alpha$ levels by any of the toxins in mature adipocytes (Figure 3C).

\section{EFFECTS OF TOXINS ON NOTCH1 AND $\beta$-CATENIN SIGNALING IN 3T3-L1 CELLS}

We previously showed that PMT downregulated Notch1 expression, while maintaining Pref1/Dlk1 and $\beta$-catenin levels in 3T3-L1 cells during differentiation (Aminova and Wilson, 2007). We next determined whether a similar effect might be observed for the other dermonecrotic toxins, DNT and CNF1. In control cells, both Pref1/Dlk1 and $\beta$-catenin levels declined during differentiation, while as was previously observed for PMT, $\beta$-catenin protein levels were maintained through day 7 of differentiation in the presence of either of the other toxins (Figure 3B). For each of the toxins, Y-27632 partially blocked the effect of the toxins on $\beta$-catenin levels.

In undifferentiated 3T3-L1 preadipocytes, Notch 1 protein levels decreased after 1 day of treatment with any of the three toxins (Figure 4A). For PMT and DNT this decrease in protein levels could be partially prevented by Y-27632, but apparently through a mechanism independent of toxin action, since Y-27632 treatment also caused an increase in Notch1 levels in control cells. Y-27632 also caused a partial increase in Notch1 mRNA levels in the case of PMT and to a lesser extent DNT, but again Y-27632 also caused a noticeable, presumably independent increase in Notch1 
A
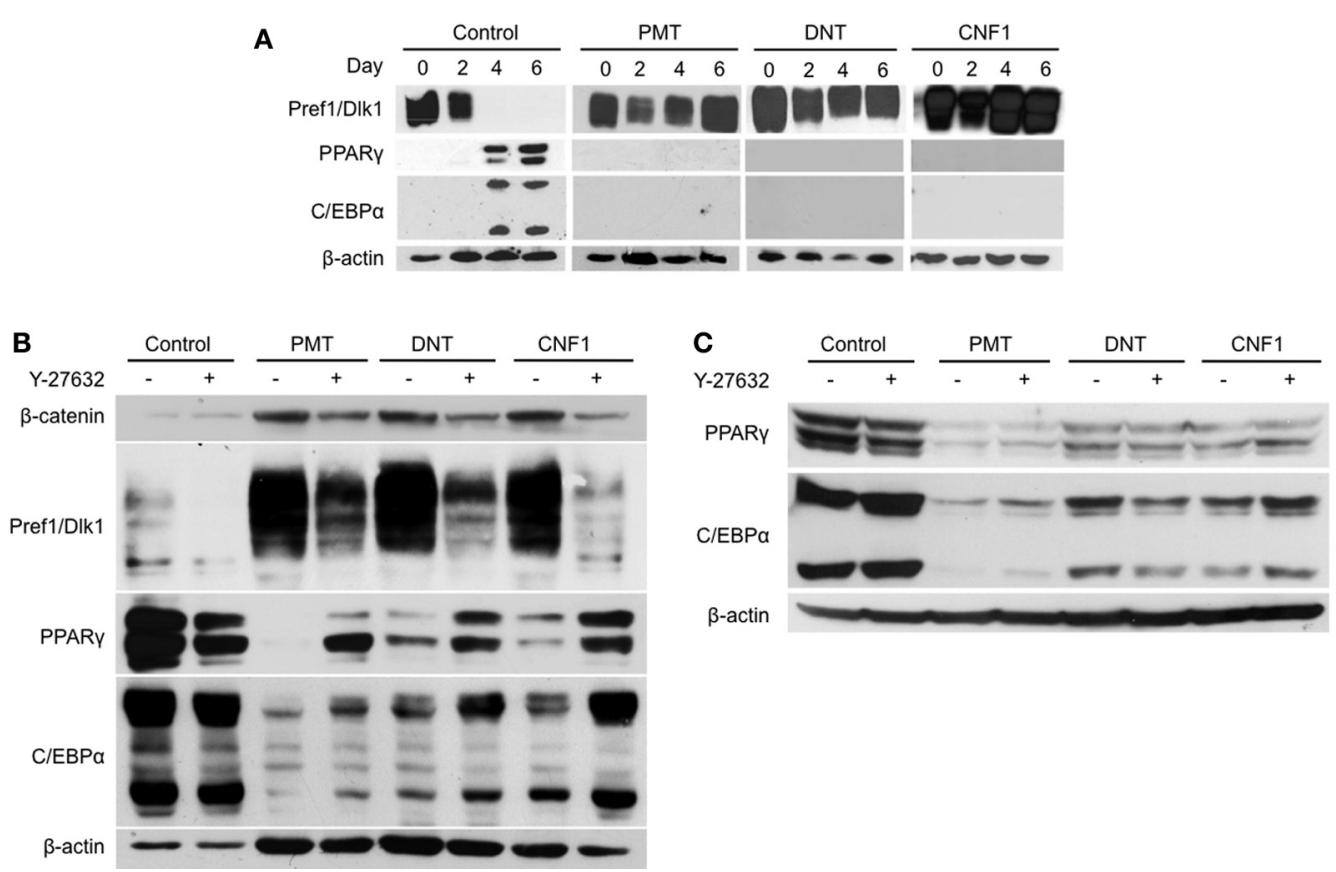

FIGURE 3 | Effect of dermonecrotic toxins on adipocyte marker expression profiles during differentiation. Confluent 3T3-L1 preadipocytes were induced to differentiate in DM, as described in Materials and Methods. On the indicated days, cell lysates were subjected to SDS-PAGE and immunoblot analysis using antibodies against $\beta$-catenin, Pref1/DIk1, PPAR $\gamma$, $\mathrm{C} / \mathrm{EBP} \alpha$, or $\beta$-actin. (A) Time-course of differentiation in the absence (control)

or presence of $1 \mathrm{nM}$ of the indicated toxin. (B) Effect of $10 \mu \mathrm{M} Y-27632$ on adipocyte marker expression profiles in preadipocytes on day 7 after differentiation induction in the absence (control) or presence of $1 \mathrm{nM}$ of the indicated toxin. (C) Effect of $10 \mu \mathrm{M}$ Y-27632 on adipocyte marker expression profiles in mature adipocytes treated on day 7 after differentiation induction without (control) or with $1 \mathrm{nM}$ of the indicated toxin and analyzed on day 8 .

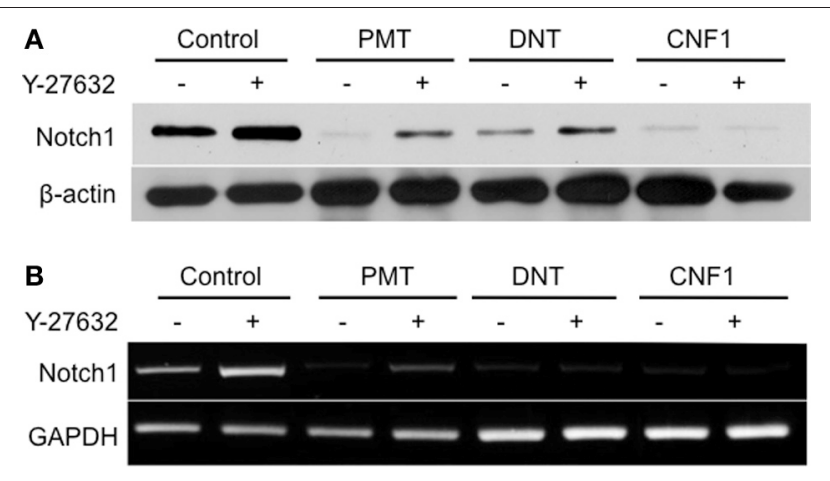

FIGURE 4 | Effect of dermonecrotic toxins on Notch1 signaling in 3T3-L1 cells. Confluent 3T3-L1 preadipocytes were treated for one day without (control) or with $1 \mathrm{nM}$ of the indicated toxin in the absence or presence of $10 \mu \mathrm{M}$ Y-27632. (A) Cell lysates were subjected to SDS-PAGE and immunoblot analysis using antibodies against Notch 1 or $\beta$-actin (as control). (B) Cell lysates were analyzed for mRNA levels for Notch1 or GAPDH (as control) by RT-PCR.

mRNA levels in control cells (Figure 4B). These results suggest that while toxin-mediated modulation of $\mathrm{C} / \mathrm{EBP} \alpha, \operatorname{PPAR} \gamma$, Pref1/Dlk1 and $\beta$-catenin protein levels occurs through activation of Rho/ROCK signaling, toxin-mediated downregulation of Notch1 does not.

\section{INVOLVEMENT OF $\mathrm{G}_{\mathrm{q}}$ AND $\mathrm{G}_{12 / 13}$ IN PMT-MEDIATED DOWNREGULATION OF NOTCH1 IN 3T3-L1 CELLS}

The involvement of Rho/ROCK signaling in dermonecrotic toxin action on Notch 1 and $\beta$-catenin signaling and on adipogenesis was fully in keeping with Rho proteins as direct targets of DNT and CNF1 (Aktories et al., 2000; Hoffmann and Schmidt, 2004) and as indirect targets of PMT (Wilson and Ho, 2011). Since PMT activates Rho proteins indirectly through activation of $\mathrm{G} \alpha_{\mathrm{q}}$ or $\mathrm{G} \alpha_{12 / 13}$ signaling (Sagi et al., 2001; Zywietz et al., 2001; Orth et al., 2005), we next considered which of these pathways was involved in PMT-mediated downregulation of Notch1. $\mathrm{G} \alpha_{\mathrm{q}}, \mathrm{G} \alpha_{12}$, and $\mathrm{G} \alpha_{13}$ were knocked down in 3T3-L1 cells by using shRNA against each of their respective shRNAs (Figure 5A). Specificity of shRNA against $\mathrm{G} \alpha_{\mathrm{q}}$ was also confirmed by knockdown of $\mathrm{G} \alpha_{\mathrm{q}}$, but not the closely related $G \alpha_{11}$ (Figure 5A). In the absence of PMT, knockdown of $\mathrm{G} \alpha_{\mathrm{q}}, \mathrm{G} \alpha_{12}$, or $\mathrm{G} \alpha_{13}$ alone in 3T3-L1 cells had no effect on Notch1 mRNA levels (Figure 5B), but in all cases PMT treatment nearly completely downregulated Notch 1 mRNA levels (Figure 5B), suggesting that PMT activates multiple pathways to mediate Notch1 mRNA downregulation. PMT treatment also completely downregulated Notch 1 protein levels in 3T3-L1 cells knocked down in $\mathrm{G}_{\mathrm{q}}$ (Figure 5C). Y-27632 only partially blocked PMT-mediated downregulation of Notch1 in 3T3-L1 cells knocked down in $\mathrm{G} \alpha_{\mathrm{q}}$ (Figure 5D), supporting that PMTmediated downregulation of Notch1 does not occur through Rho/ROCK or $\mathrm{G} \alpha_{\mathrm{q}}$ signaling. On the other hand, knockdown of 


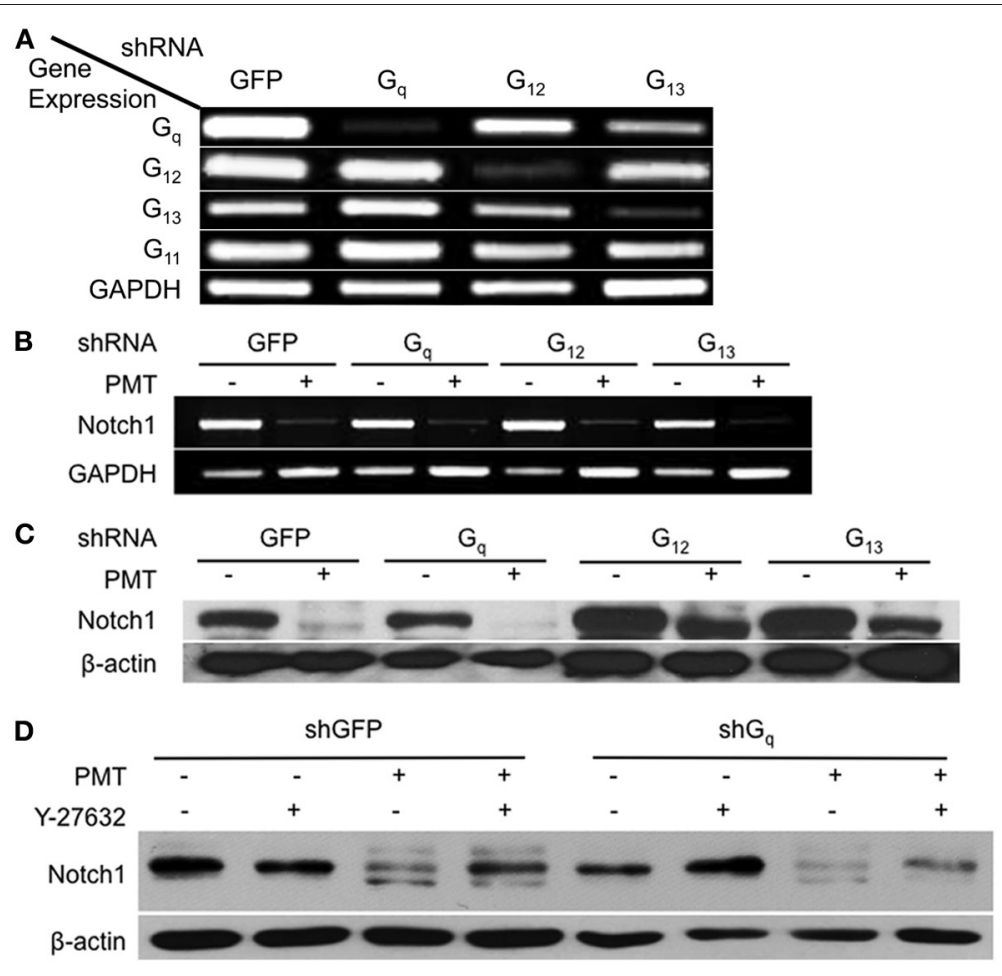

FIGURE 5 | Involvement of $\mathrm{G}_{\mathrm{q}}$ and $\mathrm{G}_{12 / 13}$-dependent Rho/ROCK signaling in Notch1 downregulation by PMT in 3T3-L1 cells. (A) 3T3-L1 preadipocytes were infected with viral particles encoding shRNA against $G \alpha_{q}$, $G \alpha_{12}, G \alpha_{13}$, or GFP (as control) and selected with puromycin for 1 week. Cell lysates were analyzed for mRNA levels for $G \alpha_{q}, G \alpha_{11}, G \alpha_{12}, G \alpha_{13}$, or GAPDH (as control) by RT-PCR. (B) Notch1 mRNA expression levels in 3T3-L1 cells expressing shRNA against $G \alpha_{q}, G \alpha_{12}, G \alpha_{13}$, or GFP and then treated without (control) or with $0.5 \mathrm{nM}$ PMT for $16 \mathrm{~h}$ and analyzed as in (A). (C) Notch1 protein levels in 3T3-L1 cells expressing shRNA against $G \alpha_{q}, G \alpha_{12}, G \alpha_{13}$, or GFP (as control) treated without (control) or with $0.5 \mathrm{nM}$ PMT for $16 \mathrm{~h}$. Cell lysates were subjected to SDS-PAGE and immunoblot analysis using anti-Notch1 or anti- $\beta$-actin (as control) antibody. (D) Notch1 protein levels in 3T3-L1 cells expressing shRNA against G $\alpha_{q}$ or GFP (as control) treated without (control) or with $0.5 \mathrm{nM}$ PMT for $16 \mathrm{~h}$ in the absence or presence of $10 \mu \mathrm{M}$ Y-27632. Cell lysates were subjected to SDS-PAGE and immunoblot analysis using anti-Notch1 or anti- $\beta$-actin (as control) antibody.
$\mathrm{G} \alpha_{12}$ or $\mathrm{G} \alpha_{13}$ blocked the downregulation of Notch1 protein levels by PMT (Figure 5C). These results suggested that $\mathrm{G} \alpha_{\mathrm{q}}$ was not the mediator of PMT-downregulation of Notch1, and instead this occurs through PMT-mediated activation of $\mathrm{G} \alpha_{12}$ and $\mathrm{G} \alpha_{13}$.

\section{DISCUSSION}

The 3T3-L1 cell line is a well-established in vitro model of adipocyte differentiation, which is characterized by expression of adipocyte-specific markers, such as PPAR $\gamma$ and $\mathrm{C} / \mathrm{EBP} \alpha$ (Rosen and Spiegelman, 2000; Otto and Lane, 2005), and downregulation of pre-adipocyte-specific markers, such as Pref1/Dlk1 (Wang et al., 2010). Our data revealed that treatment of 3T3-L1 cells during differentiation with any one of the dermonecrotic toxins resulted in blockade of adipogenesis, as evidenced by lack of lipid accumulation. Toxin treatment in all three cases also inhibited adipocyte differentiation as evidenced by downregulation of $\mathrm{PPAR} \gamma$ and $\mathrm{C} / \mathrm{EBP} \alpha$ levels and stabilization of Pref1. Moreover, the toxin-mediated effects on adipogenesis and adipocyte differentiation were Rho/ROCK-dependent as treatment with the ROCK inhibitor Y-27632 countered toxin action by all three toxins. These results point to a pivotal role of Rho/ROCK signaling in regulation of adipocyte differentiation and adipogenesis. A summary of the adipogenic signaling pathways involved in dermonecrotic toxin action are depicted in Figure 6.

DNT and the CNFs act directly on Rho proteins, while PMT acts on heterotrimeric $\mathrm{G}$ proteins that are upstream of the Rho proteins. Consistent with this, inhibition of Rho/ROCK signaling was able to prevent $76 \%$ of the inhibition by CNF1 and $53 \%$ that of DNT, but to a much lesser extent that of PMT (30\%), suggesting that additional pathways mediate the action of PMT. We thus wanted to determine which of the upstream $\mathrm{G} \alpha$ protein targets of PMT were responsible for mediating PMT action on Rho/ROCKdependent inhibition of adipogenesis. Since several earlier studies had demonstrated that stimulators of calcium signaling, such as calcium ionophores, thapsigargin and prostaglandin (PGF2 $\alpha$ ), block adipogenesis through activation of calcineurin, which could be reversed by calcineurin inhibitors (Shi et al., 2000; Neal and Clipstone, 2002; Liu and Clipstone, 2007), we previously considered the possibility that PMT-mediated inhibition of adipogenesis occurs through its known activation of $\mathrm{G}_{\mathrm{q}}$-PLC $\beta 1$-dependent calcium signaling (Aminova and Wilson, 2007). However, from those studies we determined that inhibition of calcineurin with CsA did not prevent the PMT-mediated blockade of adipogenesis or the effects of PMT on expression of PPAR $\gamma, \mathrm{C} / \mathrm{EBP} \alpha$, or Pref1 proteins, suggesting that PMT blockade of adipocyte 


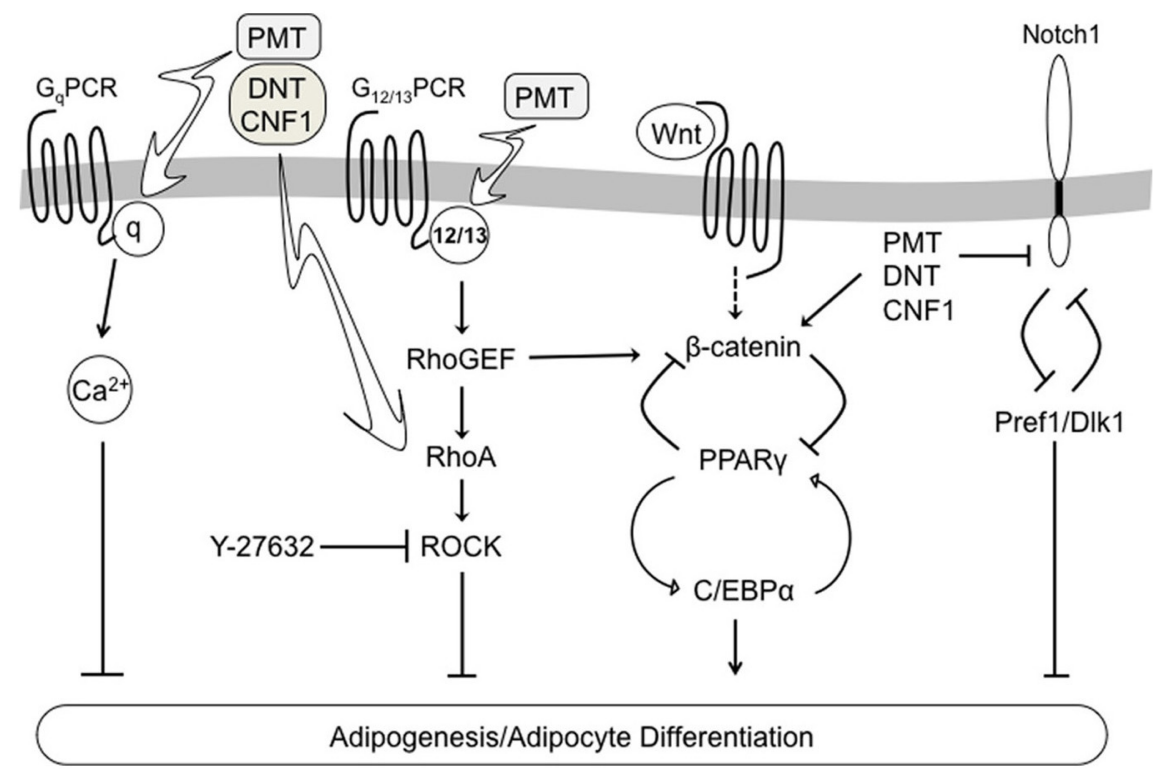

FIGURE 6 | Schematic diagram depicting a proposed model of dermonecrotic toxin action on multiple signaling pathways involved in regulating 3T3-L1 adipocyte differentiation and adipogenesis.

differentiation occurs through other pathways in addition to the $\mathrm{G}_{\mathrm{q}}$-PLC-calcium-calcineurin signaling pathway. The partial recovery of differentiation observed for PMT in the presence of Y-27632 in this study supports the notion that Rho/ROCK signaling mediates at least part of the inhibitory effect of PMT on differentiation.

Wnt/ $\beta$-catenin and Notch1 signaling pathways are differentially expressed during adipocyte differentiation (Garces et al., 1997; Bennett et al., 2002; Kawai et al., 2007), with Wnt/ßcatenin levels decreasing and Notch1 levels increasing during conversion of preadipocytes into adipocytes. Consistent with the known opposing roles that $\mathrm{Wnt} / \beta$-catenin and Notch1 signaling pathways play in regulating adipogenesis and with our previous observations for PMT (Aminova and Wilson, 2007), treatment with any one of the dermonecrotic toxins maintained $\beta$-catenin levels, while downregulating Notch1. In this study, we further investigated the role of Rho/ROCK signaling in toxinmediated effects on $\beta$-catenin and Notch 1 levels by using Y-17632. Although the $\beta$-catenin protein levels were maintained through day 7 of differentiation in the presence of any of the dermonecrotic toxins, the presence of Y-27632 dampened this effect, supporting at least a partial role for Rho/ROCK signaling in maintaining the predifferentiated state. We next explored the potential role of Rho/ROCK signaling in mediating the toxininduced downregulation of Notch1. In agreement with previously reported findings for PMT (Aminova and Wilson, 2007), Notch 1 protein levels decreased after 1 day of treatment with any one of the dermonecrotic toxins in undifferentiated 3T3-L1 preadipocytes. This decrease in Notch1 protein levels could be partially prevented by Y-27632 in the case of PMT and DNT, but not CNF1. However, this partial recovery of Notch1 expression apparently occurred through a mechanism independent of toxin action, since Y-27632 treatment also caused an increase in Notch1 levels in control cells. Similar results were observed for Notch1 mRNA levels in the presence of Y-27632. In all, these results suggest that toxin-mediated Notch1 downregulation does not occur through activation of Rho/ROCK signaling.

In this study, we further considered the possible involvement of $\mathrm{G}_{12}$ and/or $\mathrm{G}_{13}$ in mediating PMT downregulation of Notch1. Results using shRNA-mediated knockdown of $\mathrm{G}_{\mathrm{q}}, \mathrm{G}_{12}$, or $\mathrm{G}_{13}$ confirmed our previous findings that $\mathrm{G} \alpha_{\mathrm{q}}$ was not involved and instead support the involvement of both $G_{12}$ and $G_{13}$ in mediating the action of PMT on Notch1. Although we cannot rule out the possibility that the observed inhibitory action of PMT on adipocyte differentiation was mediated at least in part through PMT-activation of $\mathrm{G}_{\mathrm{i}}$ signaling, our results with knockdown of $\mathrm{G}_{12}$ and $\mathrm{G}_{13}$ clearly show that PMT-mediated downregulation of Notch 1 could be attributed almost fully to the presence of $\mathrm{G}_{12}$ and $\mathrm{G}_{13}$. Our results are also consistent with the connection between Rho/ROCK signaling and the action of lysophosphatidic acid (LPA), a known bioactive phospholipid ligand of

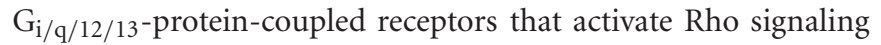
(Lee et al., 2007), and suggest that the activation of Rho/ROCK by LPA might be mediated primarily through $\mathrm{G}_{12 / 13}$ and not $\mathrm{G}_{\mathrm{q}}$ or $\mathrm{G}_{\mathrm{i}}$ signaling. LPA is known to inhibit adipogenesis through downregulation of PPAR $\gamma$ expression (Simon et al., 2005) and upregulation of $\mathrm{Wnt} / \beta$-catenin signaling through activation of the Rho/ROCK pathway (Li et al., 2011).

Mounting evidence points toward an important, yet thus far ill-defined role for chronic or previous exposure to bacterial pathogens in cancer predisposition (Lax, 2005; Vogelmann and Amieva, 2007; Nath et al., 2010) and immune modulation (Backert and Konig, 2005). In a growing number of instances, the apparent etiological agent responsible is a toxin, e.g., CagA from 
Helicobacter pylori (Murata-Kamiya, 2011). The cellular actions of the dermonecrotic toxins, PMT, DNT and the CNFs, have been implicated as risk factors to cancer predisposition (Lax, 2005; Oswald et al., 2005; Orth et al., 2007; Travaglione et al., 2008; Wilson and Ho, 2011) due to their effects on Rho-GTPase signaling pathways involved in cell morphology and motility, such as cytoskeletal rearrangements and focal adhesion, and on induction of anti-apoptotic (Bcl-2) and pro-inflammatory (NF$\mathrm{kB}$ and COX-2) protein expression (Lacerda et al., 1997; Oswald et al., 2005; Fabbri et al., 2008; Travaglione et al., 2008; Fabbri et al., 2010). In addition to its effects on cytoskeletal function, the oncogenic potential of PMT has also been linked to its strong mitogenic (Erk and p38 MAPK pathways) and/or antiapoptotic (JAK/STAT and Akt pathways) signaling activity in a number of cell types (Lax and Thomas, 2002; Lax, 2005; Oswald et al., 2005; Orth et al., 2007; Wilson and Ho, 2010, 2011), including cultured mesenchymal cells, such as mouse, rat, and human fibroblasts (Wilson et al., 2000; Orth et al., 2007; Ozgen et al., 2008; Hildebrand et al., 2010), preadipocytes (Aminova

\section{REFERENCES}

Ackermann, M. R., Register, K. B., Stabel, J. R., Gwaltney, S. M., Howe, T. S., and Rimler, R. B. (1996). Effect of Pasteurella multocida toxin on physeal growth in young pigs. Am. J. Vet. Res. 57, 848-852.

Ackermann, M. R., Stabel, J. R., Pettit, R. K., Jacobson, C. D., Elmquist, J. K., Register, K. B., Rimler, R. B., and Hilton, J. H. (1995). Reduced physeal area and chondrocyte proliferation in Pasteurella multocida toxin-treated rats. Vet. Pathol. 32, 674-682.

Aktories, K., Schmidt, G., and Just, I. (2000). Rho GTPases as targets of bacterial protein toxins. Biol. Chem. 381, 421-426.

Amano, M., Nakayama, M., and Kaibuchi, K. (2010). Rhokinase/ROCK: a key regulator of the cytoskeleton and cell polarity. Cytoskeleton 67, 545-554.

Aminova, L. R., Luo, S., Bannai, Y., Ho, M., and Wilson, B. A. (2008). The C3 domain of Pasteurella multocida toxin is the minimal domain responsible for activation of $\mathrm{Gq}$ dependent calcium and mitogenic signaling. Protein Sci. 17, 945-949.

Aminova, L. R., and Wilson, B. A. (2007). Calcineurin-independent inhibition of 3T3-L1 adipogenesis by Pasteurella multocida toxin: suppression of Notch1, stabilization of beta-catenin and pre-adipocyte factor 1. Cell. Microbiol. 9, 2485-2496.

Andersson, E. R., Sandberg, R., and Lendahl, U. (2011). Notch signaling: simplicity in design, versatility in function. Development 138, 3593-3612.
Arashima, Y., and Kumasaka, K. (2005). Pasteurellosis as zoonosis. Intern. Med. 44, 692-693.

Backert, S., and Konig, W. (2005). Interplay of bacterial toxins with host defence: molecular mechanisms of immunomodulatory signalling. Int. J. Med. Microbiol. 295, 519-530.

Bennett, C. N., Ross, S. E., Longo, K. A., Bajnok, L., Hemati, N., Johnson, K. W., Harrison, S. D., and Macdougald, O. A. (2002). Regulation of Wnt signaling during adipogenesis. J. Biol. Chem. 277, 30998-31004.

Blanco, J., Blanco, M., Alonso, M. P., Blanco, J. E., Garabal, J. I., and Gonzalez, E. A. (1992). Serogroups of Escherichia coli strains producing cytotoxic necrotizing factors CNF1 and CNF2. FEMS Microbiol. Lett. 75, 155-159.

Boney, C. M., Fiedorek, F. T. Jr., Paul, S. R., and Gruppuso, P. A. (1996). Regulation of preadipocyte factor-1 gene expression during 3T3-L1 cell differentiation. Endocrinology 137, 2923-2928.

Brockmeier, S. L., Register, K. B., Magyar, T., Lax, A. J., Pullinger, G. D., and Kunkle, R. A. (2002). Role of the dermonecrotic toxin of Bordetella bronchiseptica in the pathogenesis of respiratory disease in swine. Infect. Immun. 70, 481-490.

Cheng, P., Zhou, J., and Gabrilovich, D. (2010). Regulation of dendritic cell differentiation and function by Notch and Wnt pathways. Immunol. Rev. 234, 105-119.

Cheville, N. F., and Rimler, R. B. (1989). A protein toxin from Pasteurella

and Wilson, 2007) and osteoblasts (Sterner-Kock et al., 1995; Mullan and Lax, 1996, 1998; Gwaltney et al., 1997; Harmey et al., 2004). Wnt//-catenin, Pref1/Dlk1 and Notch 1 signaling pathways are strongly linked to cancer predisposition (Polakis, 2007; Roy et al., 2007; Jin et al., 2008), neurological and immunological dysfunctions (Cheng et al., 2010; Imayoshi et al., 2010; Yuan et al., 2010), and fat and bone developmental disorders (Prestwich and Macdougald, 2007; Wagner et al., 2011; Zanotti and Canalis, 2012). Our results describing the dysregulation of $\beta$-catenin, Pref1/Dlk1 and Notch1 protein expression by dermonecrotic toxins further add to the accumulating evidence that exposure to bacteria that produce these dermonecrotic toxins might predispose those infected individuals to potential long-term adverse outcomes.

\section{ACKNOWLEDGMENTS}

This work was supported by NIH/NIAID grant AI038396 (to Brenda A. Wilson). We thank Neil Clipstone and William Miller for helpful discussions.

multocida type D causes acute and chronic hepatic toxicity in rats. Vet. Pathol. 26, 148-157.

De Rycke, J., Gonzalez, E. A., Blanco, J., Oswald, E., Blanco, M., and Boivin, R. (1990). Evidence for two types of cytotoxic necrotizing factor in human and animal clinical isolates of Escherichia coli. J. Clin. Microbiol. 28, 694-699.

Dezso, K., Halasz, J., Bisgaard, H. C., Paku, S., Turanyi, E., Schaff, Z., and Nagy, P. (2008). Delta-like protein (DLK) is a novel immunohistochemical marker for human hepatoblastomas. Virchows Arch. 452, 443-448.

Diavatopoulos, D. A., Cummings, C. A., Schouls, L. M., Brinig, M. M., Relman, D. A., and Mooi, F. R. (2005). Bordetella pertussis, the causative agent of whooping cough, evolved from a distinct, human-associated lineage of $B$. bronchiseptica. PLoS Pathog. 1:e45. doi: 10.1371/journal.ppat.0010045

Dudet, L. I., Chailler, P., Dubreuil, J. D., and Martineau-Doize, B. (1996). Pasteurella multocida toxin stimulates mitogenesis and cytoskeleton reorganization in Swiss 3T3 fibroblasts. J. Cell. Physiol. 168, 173-182.

Fabbri, A., Travaglione, S., Falzano, L., and Fiorentini, C. (2008). Bacterial protein toxins: current and potential clinical use. Curr. Med. Chem. 15, 1116-1125.

Fabbri, A., Travaglione, S., and Fiorentini, C. (2010). Escherichia coli cytotoxic necrotizing factor 1 (stocktickerCNF1): toxin biology, in vivo applications and therapeutic potential. Toxins 2, 283-296.
Falzano, L., Fiorentini, C., Boquet, P., and Donelli, G. (1993). Interaction of Escherichia coli cytotoxic necrotizing factor type 1 (CNF1) with cultured cells. Cytotechnology 11(Suppl. 1), S56-S58.

Fiorentini, C., Fabbri, A., Flatau, G., Donelli, G., Matarrese, P., Lemichez, E., Falzano, L., and Boquet, P. (1997). Escherichia coli cytotoxic necrotizing factor 1 (CNF1), a toxin that activates the Rho GTPase. J. Biol. Chem. 272, 19532-19537.

Foged, N. T. (1992). Pasteurella multocida toxin. The characterisation of the toxin and its significance in the diagnosis and prevention of progressive atrophic rhinitis in pigs. APMIS Suppl. 25, 1-56.

Garces, C., Ruiz-Hidalgo, M. J., Bonvini, E., Goldstein, J., and Laborda, J. (1999). Adipocyte differentiation is modulated by secreted delta-like (dlk) variants and requires the expression of membrane-associated dlk. Differentiation 64, 103-114.

Garces, C., Ruiz-Hidalgo, M. J., Font De Mora, J., Park, C., Miele, L., Goldstein, J., Bonvini, E., Porras, A., and Laborda, J. (1997). Notch-1 controls the expression of fatty acidactivated transcription factors and is required for adipogenesis. J. Biol. Chem. 272, 29729-29734.

Gwaltney, S. M., Galvin, R. J., Register, K. B., Rimler, R. B., and Ackermann, M. R. (1997). Effects of Pasteurella multocida toxin on porcine bone marrow cell differentiation into osteoclasts and osteoblasts. Vet. Pathol. 34, 421-430.

Harmey, D., Stenbeck, G., Nobes, C. D., Lax, A. J., and Grigoriadis, A. E. 
(2004). Regulation of osteoblast differentiation by Pasteurella multocida toxin (PMT): a role for Rho GTPase in bone formation. J. Bone Miner. Res. 19, 661-670.

Hildebrand, D., Heeg, K., and Kubatzky, K. F. (2010). Pasteurella multocida toxin-stimulated osteoclast differentiation is B cell dependent. Infect. Immun. 79, 220-228.

Hoffmann, C., Pop, M., Leemhuis, J., Schirmer, J., Aktories, K., and Schmidt, G. (2004). The Yersinia pseudotuberculosis cytotoxic necrotizing factor (CNFY) selectively activates RhoA. J. Biol. Chem. 279, 16026-16032.

Hoffmann, C., and Schmidt, G. (2004). CNF and DNT. Rev. Physiol. Biochem. Pharmacol. 152, 49-63.

Horiguchi, Y. (2001). Escherichia coli cytotoxic necrotizing factors and Bordetella dermonecrotic toxin: the dermonecrosis-inducing toxins activating Rho small GTPases. Toxicon 39, 1619-1627.

Horiguchi, Y., Inoue, N., Masuda, M., Kashimoto, T., Katahira, J., Sugimoto, N., and Matsuda, M. (1997). Bordetella bronchiseptica dermonecrotizing toxin induces reorganization of actin stress fibers through deamidation of Gln-63 of the GTP-binding protein Rho. Proc. Natl. Acad. Sci. U.S.A. 94, 11623-11626.

Horiguchi, Y., Senda, T., Sugimoto, N., Katahira, J., and Matsuda, M. (1995). Bordetella bronchiseptica dermonecrotizing toxin stimulates assembly of actin stress fibers and focal adhesions by modifying the small GTP-binding protein rho. J. Cell. Sci. 108(Pt 10), 3243-3251.

Huang, J., Zhang, X., Zhang, M., Zhu, J. D., Zhang, Y. L., Lin, Y., Wang, K. S., Qi, X. F., Zhang, Q., Liu, G. Z., Yu, J., Cui, Y., Yang, P. Y., Wang, Z. Q., and Han, Z. G. (2007). Up-regulation of DLK1 as an imprinted gene could contribute to human hepatocellular carcinoma. Carcinogenesis 28, 1094-1103.

Imayoshi, I., Sakamoto, M., Yamaguchi, M., Mori, K., and Kageyama, R. (2010). Essential roles of Notch signaling in maintenance of neural stem cells in developing and adult brains. J. Neurosci. 30, 3489-3498.

Jin, Z. H., Yang, R. J., Dong, B., and Xing, B. C. (2008). Progenitor gene DLK1 might be an independent prognostic factor of liver cancer. Expert Opin. Biol. Ther. 8, 371-377.

Kamitani, S., Ao, S., Toshima, H., Tachibana, T., Hashimoto, M., Kitadokoro, K., Fukui-Miyazaki, A., Abe, H., and Horiguchi, Y. (2011).
Enzymatic actions of Pasteurella multocida toxin detected by monoclonal antibodies recognizing the deamidated alpha subunit of the heterotrimeric GTPase Gq. FEBS J. 278, 2702-2712.

Kawai, M., Mushiake, S., Bessho, K., Murakami, M., Namba, N., Kokubu, C., Michigami, T., and Ozono, K. (2007). Wnt/Lrp/betacatenin signaling suppresses adipogenesis by inhibiting mutual activation of PPARgamma and C/EBPalpha. Biochem. Biophys. Res. Commun. 363, 276-282.

Knust, Z., and Schmidt, G. (2010). Cytotoxic necrotizing factors (CNFs)-A growing toxin family. Toxins 2, 116-127.

Lacerda, H. M., Lax, A. J., and Rozengurt, E. (1996). Pasteurella multocida toxin, a potent intracellularly acting mitogen, induces p125FAK and paxillin tyrosine phosphorylation, actin stress fiber formation, and focal contact assembly in Swiss 3T3 cells. J. Biol. Chem. 271, 439-445.

Lacerda, H. M., Pullinger, G. D., Lax, A. J., and Rozengurt, E. (1997). Cytotoxic necrotizing factor 1 from Escherichia coli and dermonecrotic toxin from Bordetella bronchiseptica induce p21(rho)-dependent tyrosine phosphorylation of focal adhesion kinase and paxillin in Swiss 3T3 cells. J. Biol. Chem. 272, 9587-9596.

Lax, A. J. (2005). Opinion: bacterial toxins and cancer - a case to answer? Nat. Rev. Microbiol. 3, 343-349.

Lax, A. J., and Thomas, W. (2002). How bacteria could cause cancer: one step at a time. Trends Microbiol. 10, 293-299.

Lee, C. W., Rivera, R., Dubin, A. E., and Chun, J. (2007). LPA(4)/GPR23 is a lysophosphatidic acid (LPA) receptor utilizing $G(s)-, G(q) / G(i)$ mediated calcium signaling and G(12/13)-mediated Rho activation. J. Biol. Chem. 282, 4310-4317.

Li, L., Tam, L., Liu, L., Jin, T., and Ng, D. S. (2011). Wnt-signaling mediates the anti-adipogenic action of lysophosphatidic acid through cross talking with the Rho/Rho associated kinase (ROCK) pathway. Biochem. Cell Biol. 89, 515-521.

Liu, L., and Clipstone, N. A. (2007). Prostaglandin F2alpha inhibits adipocyte differentiation via a $G$ alpha q-calcium-calcineurindependent signaling pathway. $J$. Cell. Biochem. 100, 161-173.

Mills, M., Meysick, K. C., and O'Brien, A. D. (2000). Cytotoxic necrotizing factor type 1 of uropathogenic
Escherichia coli kills cultured human uroepithelial 5637 cells by an apoptotic mechanism. Infect. Immun. 68 5869-5880.

Mullan, P. B., and Lax, A. J. (1996). Pasteurella multocida toxin is a mitogen for bone cells in primary culture. Infect. Immun. 64, 959-965.

Mullan, P. B., and Lax, A. J. (1998). Pasteurella multocida toxin stimulates bone resorption by osteoclasts via interaction with osteoblasts. Calcif. Tissue Int. 63 , 340-345.

Murata-Kamiya, N. (2011). Pathophysiological functions of the CagA oncoprotein during infection by Helicobacter pylori. Microbes Infect. 13, 799-807.

Nath, G., Gulati, A. K., and Shukla, V. K. (2010). Role of bacteria in carcinogenesis, with special reference to carcinoma of the gallbladder. World J. Gastroenterol. 16, 5395-5404.

Neal, J. W., and Clipstone, N. A. (2002). Calcineurin mediates the calciumdependent inhibition of adipocyte differentiation in 3T3-L1 cells. $J$. Biol. Chem. 277, 49776-49781.

Noguchi, M., Hosoda, K., Fujikura, J., Fujimoto, M., Iwakura, H., Tomita, T., Ishii, T., Arai, N., Hirata, M., Ebihara, K., Masuzaki, H., Itoh, H., Narumiya, S., and Nakao, K. (2007). Genetic and pharmacological inhibition of Rho-associated kinase II enhances adipogenesis. J. Biol. Chem. 282, 29574-29583.

Ohnishi, T., Horiguchi, Y., Masuda, M., Sugimoto, N., and Matsuda, M. (1998). Pasteurella multocida toxin and Bordetella bronchiseptica dermonecrotizing toxin elicit similar effects on cultured cells by different mechanisms. J. Vet. Med. Sci. 60 301-305.

Orth, J. H., Aktories, K., and Kubatzky, K. F. (2007). Modulation of host cell gene expression through activation of STAT transcription factors by Pasteurella multocida toxin. J. Biol. Chem. 282, 3050-3057.

Orth, J. H., Lang, S., Taniguchi, M., and Aktories, K. (2005). Pasteurella multocida toxin-induced activation of RhoA is mediated via two families of $\mathrm{G}\{$ alpha\} proteins, $\mathrm{G}\{$ alpha $\} \mathrm{q}$ and G\{alpha\}12/13. J. Biol. Chem. 280, 36701-36707.

Orth, J. H., Preuss, I., Fester, I., Schlosser, A., Wilson, B. A., and Aktories, K. (2009). Pasteurella multocida toxin activation of heterotrimeric $\mathrm{G}$ proteins by deamidation. Proc. Natl. Acad. Sci. U.S.A. 106, 7179-7184.

Oswald, E., Nougayrede, J. P., Taieb, F., and Sugai, M. (2005). Bacterial toxins that modulate host cell-cycle progression. Curr. Opin. Microbiol. 8, 83-91.

Otto, T. C., and Lane, M. D. (2005). Adipose development: from stem cell to adipocyte. Crit. Rev. Biochem. Mol. Biol. 40, 229-242.

Ozgen, N., Obreztchikova, M., Guo, J., Elouardighi, H., Dorn, G. W. 2nd., Wilson, B. A., and Steinberg, S. F. (2008). Protein kinase D links Gq-coupled receptors to cAMP response element-binding protein (CREB)-Ser133 phosphorylation in the heart. J. Biol. Chem. 283, 17009-17019.

Polakis, P. (2007). The many ways of Wnt in cancer. Curr. Opin. Genet. Dev. 17, 45-51.

Prestwich, T. C., and Macdougald, O. A. (2007). Wnt/beta-catenin signaling in adipogenesis and metabolism. Curr. Opin. Cell Biol. 19, 612-617.

Repella, T. L., Ho, M., Chong, T. P., Bannai, Y., and Wilson, B. A. (2011). Arf6-dependent intracellular trafficking of Pasteurella multocida toxin and $\mathrm{pH}$-dependent translocation from late endosomes. Toxins 3, 218-241.

Roop, R. M. 2nd., Veit, H. P., Sinsky, R. J., Veit, S. P., Hewlett, E. L., and Kornegay, E. T. (1987). Virulence factors of Bordetella bronchiseptica associated with the production of infectious atrophic rhinitis and pneumonia in experimentally infected neonatal swine. Infect. Immun. 55, 217-222.

Rosen, E. D., and Spiegelman, B. M. (2000). Molecular regulation of adipogenesis. Annu. Rev. Cell Dev. Biol. 16, 145-171.

Roy, M., Pear, W. S., and Aster, J. C. (2007). The multifaceted role of Notch in cancer. Curr. Opin. Genet. Dev. 17, 52-59.

Sagi, S. A., Seasholtz, T. M., Kobiashvili, M., Wilson, B. A., Toksoz, D., and Brown, J. H. (2001). Physical and functional interactions of Galphaq with Rho and its exchange factors. J. Biol. Chem. 276, 15445-15452.

Schmidt, G., Goehring, U. M., Schirmer, J., Lerm, M., and Aktories, K. (1999). Identification of the C-terminal part of Bordetella dermonecrotic toxin as a transglutaminase for rho GTPases. J. Biol. Chem. 274, 31875-31881.

Schmidt, G., Goehring, U. M., Schirmer, J., Uttenweiler-Joseph, S., Wilm, M., Lohmann, M., Giese, A., Schmalzing, G., and Aktories, K. (2001). Lysine and polyamines are substrates for transglutamination of Rho by the Bordetella dermonecrotic toxin. Infect. Immun. $69,7663-7670$. 
Shi, H., Halvorsen, Y. D., Ellis, P. N., Wilkison, W. O., and Zemel, M. B. (2000). Role of intracellular calcium in human adipocyte differentiation. Physiol. Genomics 3, 75-82.

Simon, M. F., Daviaud, D., Pradere, J. P., Gres, S., Guigne, C., Wabitsch, M., Chun, J., Valet, P., and Saulnier-Blache, J. S. (2005). Lysophosphatidic acid inhibits adipocyte differentiation via lysophosphatidic acid 1 receptordependent down-regulation of peroxisome proliferator-activated receptor gamma2. J. Biol. Chem. 280, 14656-14662.

Sterner-Kock, A., Lanske, B., Uberschar, S., and Atkinson, M. J. (1995). Effects of the Pasteurella multocida toxin on osteoblastic cells in vitro. Vet. Pathol. 32, 274-279.

Sul, H. S. (2009). Minireview: pref-1, role in adipogenesis and mesenchymal cell fate. Mol. Endocrinol. 23, 1717-1725.

Thurston, J. R., Rimler, R. B., Ackermann, M. R., and Cheville, N. F. (1992). Use of rats to compare atrophic rhinitis vaccines for protection against effects of heatlabile protein toxin produced by Pasteurella multocida serogroup D. Vet. Immunol. Immunopathol. 33, 155-162.

Travaglione, S., Fabbri, A., and Fiorentini, C. (2008). The Rhoactivating CNF1 toxin from pathogenic $E$. coli: a risk factor for human cancer development? Infect. Agent. Cancer 3, 4.

Vogelmann, R., and Amieva, M. R. (2007). The role of bacterial pathogens in cancer. Curr. Opin. Microbiol. 10, 76-81.

Wagner, E. R., Zhu, G., Zhang, B. Q., Luo, Q., Shi, Q., Huang, E., Gao, Y., Gao, J. L., Kim, S. H., Rastegar, F., Yang, K., He, B. C., Chen, L., Zuo, G. W., Bi, Y., Su, Y., Luo, J., Luo, X., Huang, J., Deng, Z. L., Reid, R. R., Luu, H. H., Haydon, R. C., and He, T. C. (2011). The therapeutic potential of the Wnt signaling pathway in bone disorders. Curr. Mol. Pharmacol. 4, 14-25.

Walker, K. E., and Weiss, A. A. (1994). Characterization of the dermonecrotic toxin in members of the genus Bordetella. Infect. Immun. 62, 3817-3828.

Wang, Y., Hudak, C., and Sul, H. S. (2010). Role of preadipocyte factor 1 in adipocyte differentiation. Clin. Lipidol. 5, 109-115.

Wilson, B. A., Aminova, L. R., Ponferrada, V. G., and Ho, M. (2000). Differential modulation and subsequent blockade of mitogenic signaling and cell cycle progression by Pasteurella multocida toxin. Infect. Immun. 68, 4531-4538.

Wilson, B. A., and Ho, M. (2010). Recent insights into Pasteurella multocida toxin and other G-proteinmodulating bacterial toxins. Future Microbiol. 5, 1185-1201.
Wilson, B. A., and Ho, M. (2011). Cellular and molecular action of the mitogenic protein-deamidating toxin from Pasteurella multocida. FEBS J. 278, 4616-4632.

Woolfrey, B. F., and Moody, J. A. (1991). Human infections associated with Bordetella bronchiseptica. Clin. Microbiol. Rev. 4, 243-255.

Xu, X., Liu, R. F., Zhang, X., Huang, L. Y., Chen, F., Fei, Q. L., and Han, Z. G. (2012). DLK1 as a potential target against cancer stem/progenitor cells of hepatocellular carcinoma. Mol. Cancer Ther. 11, 629-638.

Yanai, H., Nakamura, K., Hijioka, S., Kamei, A., Ikari, T., Ishikawa, Y., Shinozaki, E., Mizunuma, N., Hatake, K., and Miyajima, A. (2010). Dlk-1, a cell surface antigen on foetal hepatic stem/progenitor cells, is expressed in hepatocellular, colon, pancreas and breast carcinomas at a high frequency. J. Biochem. 148, 85-92.

Yuan, J. S., Kousis, P. C., Suliman, S., Visan, I., and Guidos, C. J. (2010). Functions of notch signaling in the immune system: consensus and controversies. Annu. Rev. Immunol. 28, 343-365.

Zanotti, S., and Canalis, E. (2012) Notch regulation of bone development and remodeling and related skeletal disorders. Calcif. Tissue Int. 90, 69-75.
Zywietz, A., Gohla, A., Schmelz, M., Schultz, G., and Offermanns, S. (2001). Pleiotropic effects of Pasteurella multocida toxin are mediated by Gq-dependent and -Independent mechanisms. Involvement of $\mathrm{Gq}$ but not G11. J. Biol. Chem. 276, 3840-3845.

Conflict of Interest Statement: The authors declare that the research was conducted in the absence of any commercial or financial relationships that could be construed as a potential conflict of interest.

Received: 27 January 2012; accepted: 22 May 2012; published online: 05 June 2012.

Citation: Bannai $Y$, Aminova LR, Faulkner MJ, Ho $M$, and Wilson $B A$ (2012) Rho/ROCK-dependent inhibition of 3T3-L1 adipogenesis by $G$-protein-deamidating dermonecrotic toxins: differential regulation of Notch1, Pref1/Dlk1, and $\beta$-catenin signaling. Front. Cell. Inf. Microbio. 2:80. doi: $10.3389 /$ fcimb. $^{2012.00080}$

Copyright (c) 2012 Bannai, Aminova, Faulkner, Ho and Wilson. This is an open-access article distributed under the terms of the Creative Commons Attribution Non Commercial License, which permits non-commercial use, distribution, and reproduction in other forums, provided the original authors and source are credited. 